\title{
Distinct domains of the Candida albicans adhesin Eap1p mediate cell-cell and cell-substrate interactions
}

Correspondence

Sean P. Palecek

palecek@engr.wisc.edu

Received 1 October 2007

Revised 22 December 2007

Accepted 10 January 2008
Fang Lit and Sean P. Palecek

Department of Chemical and Biological Engineering, University of Wisconsin - Madison, Madison, WI 53706, USA

The adhesion of Candida albicans to host tissues contributes to its virulence, and adhesion to tissues or medical devices is a necessary step in biofilm formation. EAP1 encodes a glycosylphosphatidylinositol (GPI)-anchored glucan-cross-linked cell wall protein that mediates adhesion of C. albicans to various materials and cells, and appears to be required for C. albicans biofilm formation in vitro and in vivo. In this study, we demonstrated that the Eap1p N-terminal signal peptide and C-terminal GPI-anchor sequences result in similar protein localization in Saccharomyces cerevisiae and C. albicans. To investigate the contribution of different Eap $1 p$ domains to adhesion, we expressed Eap1p domain deletion mutants in non-adherent $S$. cerevisiae strains. The $\mathrm{N}$-terminal domain mediates yeast cell-cell adhesion and invasive growth. Two Ser/Thr-rich domains containing tandem repeats were required to project the $\mathrm{N}$-terminal region into the extracellular environment and to mediate adhesion to polystyrene. The $\mathrm{N}$-terminal tandem repeat domain mediated adhesion to mammalian epithelial cells and promoted $S$. cerevisiae pseudohyphal growth. These results suggest a modular structure of Eap1p in which each domain serves multiple, often distinct, functions.

\section{INTRODUCTION}

Candida albicans is the leading cause of candidiasis, most often manifesting as superficial mucosal infections. Candida spp. are also major agents of systemic bloodstream infections, causing $8 \%$ of all such nosocomial infections in the USA (Edmond et al., 1999; Jarvis, 1995; Pfaller et al., 1998; Pfaller \& Diekema, 2007). C. albicans is also the most common fungus associated with biofilm formation on bioprosthetic materials (Lopez-Ribot, 2005). Cells in biofilms are much more resistant to antifungal agents, including amphotericin B and azoles (Al-Fattani \& Douglas, 2004; Hawser \& Douglas, 1995).

Adhesion between $C$. albicans cells and materials or host cells has been implicated as an early step in biofilm formation. Adhesion of C. albicans to mammalian tissues is also considered to be a very important determinant of pathogenesis (Calderone \& Fonzi, 2001). C. albicans glycosylphosphatidylinositol-dependent cell wall proteins (GPI-CWP) are characterized by the presence of an $\mathrm{N}$ terminal signal peptide and a C-terminal sequence

tPresent address: Department of Molecular Pharmacology and Experimental Therapeutics, Mayo Clinic, 200 1st St SW, Rochester MN 55905, USA.

Abbreviations: GPI, glycosylphosphatidylinositol; GPI-CWP, glycosylphosphatidylinositol-dependent cell wall protein; XTT, 2,3-bis(2-methoxy-4nitro-5-sulfophenyl)-2H-tetrazolium-5-carboxanilide. signalling GPI anchor attachment (Dranginis et al., 2007). Many of these proteins are involved in mediating the adhesion of $C$. albicans cells to host materials and/or inert surfaces (Fu et al., 2002; Gaur \& Klotz, 1997; Phan et al., 2007; Staab et al., 1999; Zhao et al., 2005, 2007). Previous studies suggest that the N-terminal domains of the adhesins that are members of the GPI-CWP family mediate binding to substrates and the GPI anchor is required for incorporating these proteins into the cell wall (Frieman et al., 2002; Loza et al., 2004). These adhesins, in many cases, also contain serine/threonine-rich tandem repeat domains essential for proper presentation of the $\mathrm{N}$ terminal substrate-binding sites (Frieman et al., 2002; Loza et al., 2004). However, the conserved Als tandem repeats in Als5p facilitate adhesion to fibronectin and greatly increase cell-cell aggregation (Rauceo et al., 2006).

Previous studies have demonstrated that the C. albicans Eap1p is a member of the GPI-CWP family (Li et al., 2007). The C. albicans Eap1p adhesin was originally identified because of its ability to mediate adhesion to polystyrene when the EAP1 gene was expressed in a flocculin-deficient Saccharomyces cerevisiae strain. EAP1 expression enhanced attachment of $S$. cerevisiae to HEK293 kidney epithelial cells and played an additional role in mediating interactions between $S$. cerevisiae and C. albicans cells ( $\mathrm{Li} \&$ Palecek, 2003, 2005). Expression of EAP1 in a C. albicans efg1/efg1 mutant was able to restore its partially reduced 
adhesion to HEK293 epithelial cells (Li \& Palecek, 2003). Deleting EAP1 in C. albicans reduced cell adhesion to polystyrene and epithelial cells in a gene dosage-dependent manner. C. albicans eap1/eap1 mutant cells were also defective in cell-cell adhesion when those cells were grown in a parallel-plate flow chamber under shear flow ( $\mathrm{Li}$ et al., 2007). The defect in Eap1p-mediated adhesion was also associated with a defect in C. albicans biofilm formation in an in vitro and an in vivo model (Li et al., 2007). In C. albicans, EAP1 is expressed at similar levels in both yeast and filamentous forms (Li et al., 2007); however, the relative expression of EAP1 compared to other adhesins and the localization of Eap1p remain unknown. Many insights into the functions of $C$. albicans adhesins have been derived in $C$. albicans (Fu et al., 2002; Li et al., 2007; Phan et al., 2007; Staab et al., 1999; Zhao et al., 2005, 2007). Heterologous expression of $C$. albicans adhesins in S. cerevisiae has also proven valuable in exploring C. albicans adhesive function (Loza et al., 2004; Rauceo et al., 2006). Eap1p mediates adhesion to many substrates, including synthetic materials, yeast cells and mammalian cells, when expressed in both $S$. cerevisiae and C. albicans, suggesting that $S$. cerevisiae may be used as a relevant heterologous system to study the adhesive function of Eap1p in C. albicans.

In the experiments described in this paper, we constructed deletion mutants of EAP1 and expressed wild-type Eap1p and Eaplp mutants in an adhesin-deficient $S$. cerevisiae strain to study the mechanisms by which Eap1p mediates adhesion and define the critical functions of the domains of Eap1p in the context of adhesion. We demonstrated that different regions of Eaplp mediated adhesion to distinct substrates.

\section{METHODS}

Strains and media. Escherichia coli strain DH5 $\alpha$ was used for general recombinant techniques according to protocols described by Sambrook et al. (1989). S. cerevisiae haploid strain SPY308 ( $\Sigma 1278$ b
MATa ura3-52 his3:: hisG leu2:: hisG flo8:: $\mathrm{kan}^{r}$ ), diploid strain

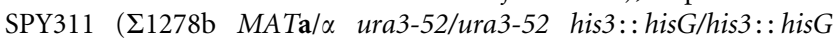
leu2:: hisG/LEU2 flo8:: kan $/$ flo8::HIS3) and strain BJ5464 (BJ $\alpha)$

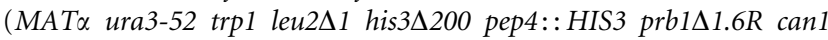
$G A L)$ were used as the hosts for all mutants. Yeast strains were routinely cultured in YPD medium ( $1 \%$ yeast extract, $2 \%$ peptone, $2 \%$ glucose) at $30{ }^{\circ} \mathrm{C}$. Synthetic complete media lacking specific nutrients and filamentous growth media have been described previously (Ahn et al., 1999; Kron et al., 1994). Synthetic lowammonium (SLAD) medium contained $50 \mu \mathrm{M}$ ammonium sulfate. Uracil was added to SLAD medium to a concentration of $0.2 \mathrm{mM}$ to make SLAD + Ura. Galactose was added to media to replace glucose in order to express genes within plasmids containing the $S$. cerevisiae GAL1 promoter. Yeast cells were transformed using lithium acetate transformation (Gietz et al., 1992). Pseudohyphal growth assay and agar invasion assay were performed as previously described ( $\mathrm{Li} \&$ Palecek, 2003).

Plasmid construction. Sequences of all oligonucleotides used in cloning are provided in Table 1. Plasmids designed to express GFP fusions to the $\mathrm{N}$ - and truncated C-termini of EAP1 were constructed in a similar manner to that described by Mao et al. (2003). A partial ORF encoding the $\mathrm{N}$-terminal 42 amino acids of Eaplp was amplified from C. albicans SC5314 genomic DNA. This PCR product was digested with PacI and SpeI and ligated into pHwp1Sig.GFP.GPI (Mao et al., 2003) to yield pEap1Sig.GFP.Hwp1GPI. A partial ORF encoding the C-terminal 47 amino acids of Eaplp was amplified from C. albicans SC5314 genomic DNA. This PCR product was digested with BamHI and SmaI and ligated into pEap1Sig.GFP.Hwp1GPI to generate pEAP1.Sig.GFP.GPI. pEAP1.Sig.GFP.NOGPI is essentially identical to pEAP1.Sig.GFP.GPI except that 21 amino acid residues from the C-terminus of Eaplp encoding the GPI anchor signal were deleted. The sequences between the PacI and SmaI sites encoding Eap1p/GFP fusion proteins were also PCR-amplified from pEAP1.Sig.GFP.GPI and pEAP1.Sig.GFP.NOGPI then cloned into pCT302 (Boder et al., 2000) cut with EcoRI and XhoI to generate pCTEAP1.Sig.GFP.GPI and pCTEAP1.Sig.GFP.NOGPI, respectively.

The signal peptide of EAP1 was cloned in pCTEAP1.Sig.GFP.GPI as an EcoRI-SpeI fragment generated by PCR with the oligonucleotides EAP1.5primer.EcoRI and EAP1.HA.Sig3, which contains the sequence encoding the haemagglutinin (HA) epitope of the influenza virus, to generate pCTEap1.HA.Sig.GFP.GPI. The PCR products produced by amplifying the genomic DNA of C. albicans strain SC5314 with oligonucleotides EAP1.3primer.XhoI and EAP1-1, EAP1-2, EAP1-3,

Table 1. Oligonucleotide primers used in this study

\begin{tabular}{|ll|}
\hline Primer & \multicolumn{1}{c|}{ Sequence $\left(\mathbf{5}^{\prime} \mathbf{-} \mathbf{3}^{\prime} \mathbf{)}\right.$} \\
\hline EAP1.5primer.EcoRI & GCGAGAGAATTCATGAAAGTTTCTCAAATTTTACCA \\
EAP1.3primer.XhoI & GAGAGCCTCGAGTCACATAAAGTAGACTAATGCAGCC \\
EAP1-1 & GTGCGGACTAGTAATTCCTACCCAGGCCAATA \\
EAP1-2 & GTGCGGACTAGTTATTGTCCATTGACATCAACT \\
EAP1-3 & GTGCGGACTAGTGCATCCACTGAGACAGCTTCC \\
EAP1-4 & GTGCGGACTAGTCCTAACACGTCCACACCAGCT \\
EAP1-5 & GTGCGGACTAGTGGCACTGAAGCTACTCCAGTT \\
EAP1-1-Right & GAGGAAGGATCCAACTGGGATTGAAAGAACAC \\
EAP1-2-Right & GAGGAAGGATCCTTGAGTAGTAACTGGAGTAGC \\
EAP1-3-Right & GAGGAAGGATCCTGTGGACGTGTTAGGAACTG \\
EAP1-4-Right & GAGGAAGGATCCGGAAGCTGTCTCAGTGGATGC \\
EAP1-5-Right & GAGGAAGGATCCTGGAGTTGATGTCAATGGACA \\
EAP1.HA.Sig3 & GTGCGGACTAGTAGCGTAGTCTGGAACGTCGTATGGGTATGGG- \\
& TATGAATTTTGTTGTTCAGAAA \\
\hline
\end{tabular}


EAP1-4, and EAP1-5, respectively, were digested with SpeI and XhoI and ligated into pCTEap1.HA.Sig.GFP.GPI to yield HA-Eap1p, HAEap $1 \mathrm{p} \Delta 1 \mathrm{~N}$, HA-Eap $1 \mathrm{p} \Delta 2 \mathrm{~N}$, HA-Eap $1 \mathrm{p} \Delta 3 \mathrm{~N}$ and HA-Eap1p $\Delta 4 \mathrm{~N}$, respectively. The PCR products produced by amplifying the genomic DNA of C. albicans strain SC5314 with oligonucleotides EAP1-1 and EAP1-1-Right, EAP1-2-Right, EAP1-3-Right, EAP1-4-Right, and EAP1-5-Right, respectively, were digested with SpeI and BamHI and ligated into pCTEap1.HA.Sig.GFP.GPI to yield HA-Eaplp.GPI, HAEap $1 p \Delta 1$ C.GPI, HA-Eaplp $\Delta 2$ C.GPI, HA-Eap1p $\Delta 3$ C.GPI and HAEaplp $\Delta 4$ C.GPI, respectively. pCTEap1.HA.Sig.GFP.GPI was digested with SpeI and BamHI. The fragments amplified by PCR with oligonucleotides EAP1-2 and EAP1-4-Right and oligonucleotides EAP1-4 and EAP1-2-Right were cloned into this digested vector to generate HA-Eap1.Sig.TR1.GPI and HA-Eap1.Sig.TR2.GPI, respectively. For all constructs in which fragments were generated by PCR, the final constructs were verified by DNA sequence analysis.

Microscopy. To detect Eaplp-GFP fusion proteins and HA-tagged Eap1p mutant proteins, constructs were transformed into S. cerevisiae BJ5464 (BJ $\alpha)$ cells and uracil prototrophs were selected on minimal glucose plates. Cells carrying these plasmids were cultured overnight at $30{ }^{\circ} \mathrm{C}$ in minimal medium containing galactose. The cells were then washed in PBS and immunofluorescence staining was performed as previously described ( $\mathrm{Li}$ et al., 2007). To visualize yeast cell aggregates, cells were resuspended in PBS buffer and placed onto a microscope slide for photographing.

\begin{abstract}
Western analysis. Yeast cells expressing each Eaplp-GFP fusion construct were cultured as described above and harvested by centrifugation. To analyse the Eaplp-GFP fusion proteins in medium, the supernatant was concentrated using $10 \mathrm{kDa}$ molecular mass cutoff Microcon centrifugal filters. Yeast cell walls were isolated according to the method of Mao et al. (2003). The proteins released into the supernatant by laminarinase digestion or from concentrated cell-free medium were subjected to SDS-PAGE and analysed by Western blotting using the ECL Western blot kit (Amersham) and an anti-GFP monoclonal antibody.
\end{abstract}

Polystyrene binding assay. Yeast cells were cultured overnight at $30{ }^{\circ} \mathrm{C}$ in minimal medium containing galactose. After brief sonication to break cell clumps, equal number of cells was added to the wells of 24-well plates and incubated in sodium phosphate buffer $(\mathrm{pH}$ 6.0) for $2 \mathrm{~h}$. Plates were washed a few times and the number of cells remaining attached was quantified by an XTT [2,3-bis(2-methoxy-4nitro-5-sulfophenyl)-2 $\mathrm{H}$-tetrazolium-5-carboxanilide]-reduction assay (Ramage et al., 2001).

\section{RESULTS}

\section{Eap1p/GFP fusion protein is localized to the cell wall in S. cerevisiae}

EAP1 encodes a GPI-anchored, glucan-cross-linked cell wall protein in C. albicans ( $\mathrm{Li}$ et al., 2007). Mao et al. (2003) demonstrated that green fluorescent protein (GFP) fused to the $\mathrm{N}$ - and C-termini of the C. albicans GPIanchored cell wall proteins Hwp1p, Als3p and Rbt5p was localized to the $C$. albicans cell wall. We used this approach to verify the cell wall localization of Eaplp in S. cerevisiae. A synthetic GFP (Cormack et al., 1997) was fused between 42 amino acid residues from the $\mathrm{N}$-terminus and 47 amino acid residues from the C-terminus of Eaplp. The resulting fusion protein was expressed in $S$. cerevisiae under regulation of the GAL1 promoter. The pCTEAP1.Sig. GFP.GPI transformants expressing this fusion protein showed localized fluorescence at the cell surface (Fig. 1a), demonstrating that the EAP1-derived sequences were capable of targeting the fusion protein to the cell surface. We next used GFP fused to the 42 amino acids from the Nterminus but lacking the C-terminal sequence (pCTEAP1.Sig.GFP.NOGPI) to investigate if the GFP fusion was secured to the cell surface via a GPI anchor. This fusion did not localize to the cell wall, but was found inside the cell, appearing concentrated in extranuclear organelles (Fig. 1a). We tested the cell-free medium of the pCTEAP1.Sig.GFP.NOGPI transformants for secretion of the GFP fusion by Western blotting with an anti-GFP monoclonal antibody. The pCTEAP1.Sig.GFP.NOGPI transformants secreted a protein that was detected by the anti-GFP antibody and whose size corresponded to that of the fusion protein, whereas GFP was not detected in culture supernatants of the pCTEAP1.Sig.GFP.GPI transformants (Fig. 1a). To address whether the Eap1-GFP fusion proteins anchored to the plasma membrane or were incorporated in the cell wall, purified cell walls from $S$. cerevisiae strains transformed with GFP constructs were digested with $\beta$-glucanase. The GFP fusion protein was released from the cell walls of the pCTEAP1.Sig.GFP.GPI transformants and detected with anti-GFP antibodies (Fig. 1c). In control experiments, immunoreactive GFP proteins were not found in $\beta$-glucanase-treated cell walls of cells transformed with pCTEAP1.Sig.GFP.NOGPI nor in samples treated with buffer alone (Fig. 1c). The N- and Ctermini of Eap1p were also required to localize Eap1p in $C$. albicans cell wall (Li et al., 2007). Based on these results, we concluded that Eap1p N-terminal and C-terminal sequences result in similar protein localization at the cell surface in S. cerevisiae and C. albicans.

\section{Two Eap1p Ser/Thr-rich domains containing tandem repeats are required for projecting the $\mathrm{N}$ - terminal region into the extracellular environment}

Two Ser/Thr-rich regions containing a variable number of tandem repeats divide Eap1p into five regions (Fig. 2). The $\mathrm{N}$-terminal region contains a signal peptide and may also contain a substrate-binding domain based on the common structures among adhesins. Two alleles of EAP1 exist in $C$. albicans strain SC5314. The segment following the $\mathrm{N}$ terminal region consists of $\sim 90$ and $\sim 17$ copies of an imperfect peptide sequence, STPATE (Fig. 2, boxes with vertical lines), in the long and short allele, respectively. The long allele was used in this study. The region following this segment is homologous to the putative N-terminal adhesion domain (Fig. 2, grey boxes). The C-terminal tandem-repeat domain consists of $\sim 12$ copies of an imperfect peptide sequence, TPAAPGTPVESQPVIPGTET (Fig. 2, hatched boxes). The C-terminal region contains a GPI anchor addition signal involved in cross-linking Eap1p to the yeast cell wall (Fig. 2). To investigate the function of each domain in Eaplp, we constructed a series of 
(a)
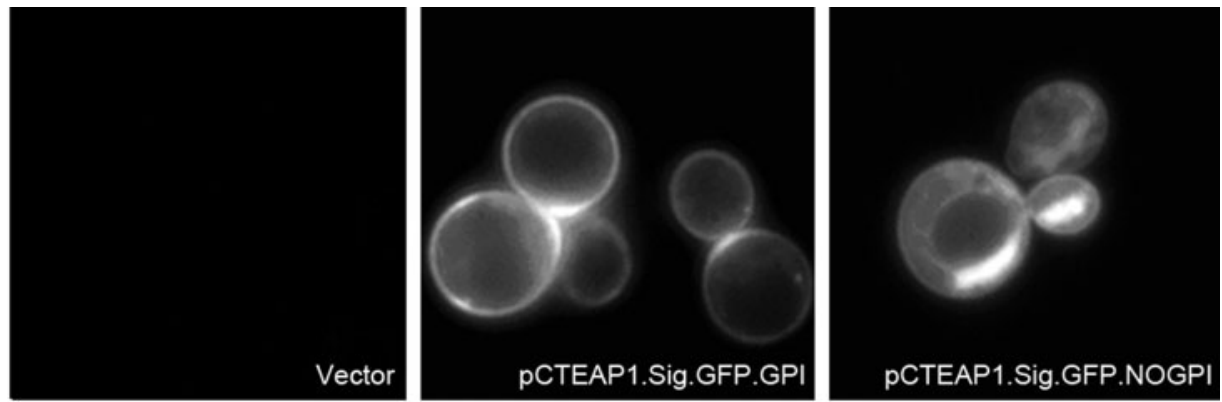

(b)
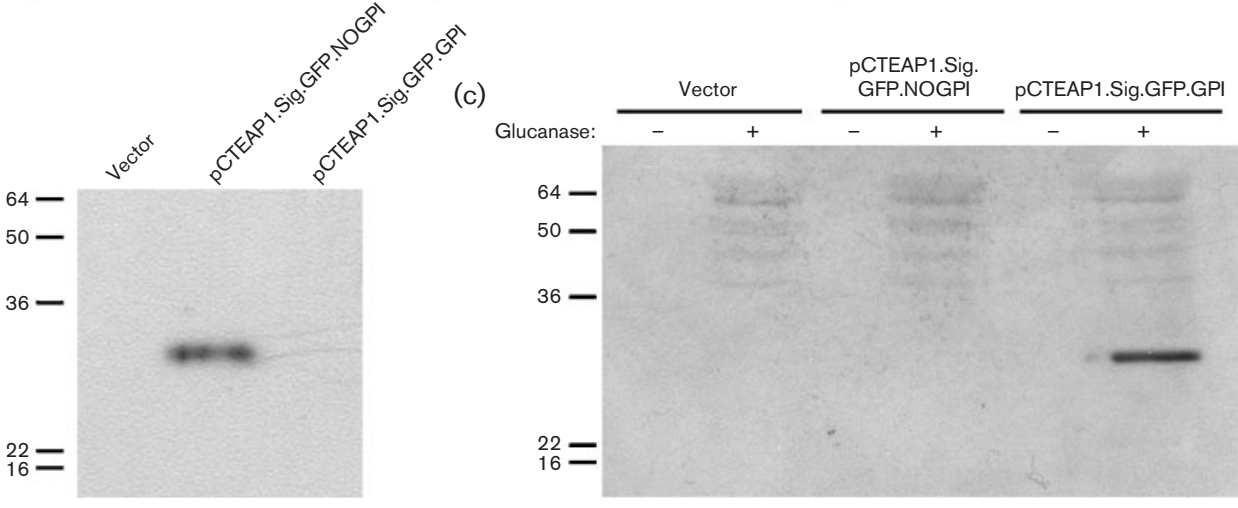

Fig. 1. Cell wall localization of Eap1p-GFP fusion proteins. (a) Epifluorescence microscopy analysis of S. cerevisiae strain BJ5464 transformed with empty vector, plasmid pCTEAP1.Sig.GFP.GPI and pCTEAP1.Sig.GFP.NOGPI. Plasmid pCTEAP1.Sig.GFP.GPI encodes a yeast-enhanced GFP fused to 42 amino acid residues from the N-terminus of Eap1p and 47 amino acid residues from the C-terminus of Eap1p. Plasmid pCTEAP1.Sig.GFP.NOGPI encodes a protein identical to pCTEAP1.Sig.GFP.GPI except that 21 amino acid residues from the C-terminus of Eap1p encoding the GPI anchor signal were deleted. The transformants were grown in minimal medium containing galactose for $20 \mathrm{~h}$ at $20{ }^{\circ} \mathrm{C}$ prior to imaging. Images were taken with identical exposure. (b) Analysis of the cell-free supernatant from S. cerevisiae strain BJ5464 transformed with plasmid pCTEAP1.Sig.GFP.GPI, pCTEAP1.Sig.GFP.NOGPI, and empty vector pCT302. The fractions were run on a $12 \%$ SDS-PAGE gel and visualized by Western blotting with an anti-GFP monoclonal antibody. (c) Cell wall extractions of $S$. cerevisiae strain BJ5464 transformed with plasmid pCTEAP1.Sig.GFP.GPI, pCTEAP1.Sig.GFP.NOGPI, and empty vector pCT302. Cell walls were extracted twice in boiling SDS and digested with $\beta$-1,3-glucanase $(+)$ or no enzyme $(-)$, then separated into pellet and supernatant fractions. The glucanase-treated and untreated supernatant fractions were loaded on a $12 \%$ SDS-PAGE gel and visualized by Western blotting with an anti-GFP monoclonal antibody. Positions of size standards $(\mathrm{kDa})$ are shown on the left in (b) and (c).

HA-tagged Eap1p deletion mutants by sequentially deleting one domain from the $\mathrm{N}$-terminus or the $\mathrm{C}$-terminus while leaving the signal peptide and the GPI anchor signal intact to ensure localization to the cell wall (Fig. 2). The HA epitope was engineered into the EAP1 coding sequence Cterminal to the 30th amino acid residue.

We monitored the surface expression of the Eap1p mutants expressed in S. cerevisiae by fluorescence microscopy. A monoclonal antibody directed against the HA epitope recognized HA-Eaplp, HA-Eaplp $\Delta 1 \mathrm{~N}$, HA-Eaplp $\Delta 2 \mathrm{~N}$, HA-Eaplp $\Delta 3 \mathrm{~N}$ (Fig. 3a), HA-Eaplp.GPI, HA-Eaplp $\Delta 1 \mathrm{C}$. GPI, HA-Eap1p $\Delta 2$ C.GPI and HA-Eap1p $\Delta 3$ C.GPI (Fig. 3b) on the surface of yeast, but the antibody did not bind to yeast transformed with the plasmid encoding HAEaplp $\Delta 4 \mathrm{~N}$ and HA-Eap1p $\Delta 4$ C.GPI (Fig. 3a, b). The HA epitope could also be detected by the anti-HA antibody when only the $\mathrm{N}$-terminal or the $\mathrm{C}$-terminal tandem repeat domain was expressed in the presence of the signal peptide and the GPI anchor addition signal (Fig. 3c). These results suggest that both the $\mathrm{N}$-terminal and the $\mathrm{C}$-terminal tandem repeat domains can project the $\mathrm{N}$-terminus of the protein away from the cell and into the extracellular environment, where it is accessible to antibody binding. We also verified the surface expression of all the constructs using fluorescence-activated cell sorting (FACS) after sonication to break cell clumps, and a similar amount of each Eap1p mutant protein was found on the surface of yeast cells in which the construct was accessible to the anti-HA antibody (data not shown).

\section{The $\mathbf{N}$-terminal domain mediates haploid invasive growth and yeast cell-cell adhesion}

Flo8p is required for haploid invasive growth in $\Sigma 1278 \mathrm{~b}$ S. cerevisiae cells (Lambrechts et al., 1996; Liu et al., 1996; Lo \& Dranginis, 1998). A S. cerevisiae haploid flos strain 
(a)

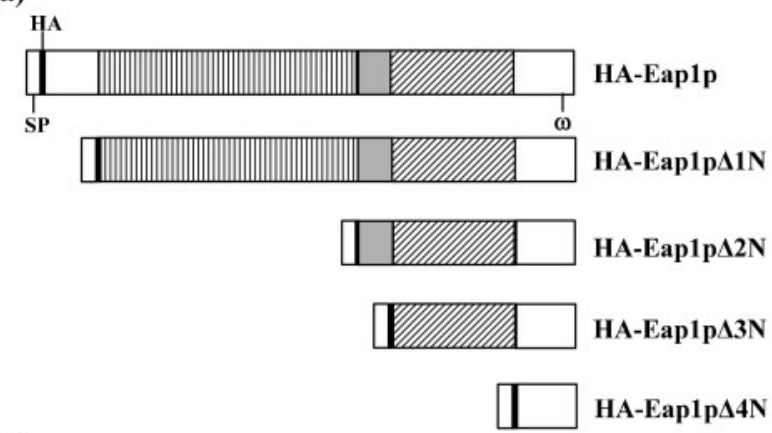

(b)

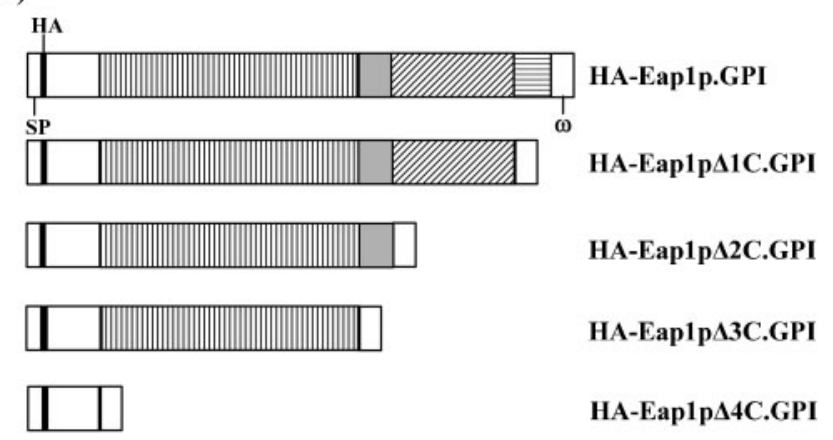

(c)

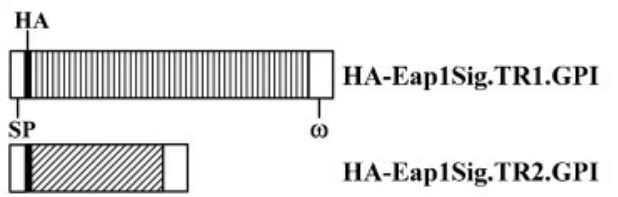

Fig. 2. Schematic of (a) N-terminal mutant Eap1p proteins, (b) Cterminal mutant Eap1 $p$ proteins and (c) tandem repeats of Eap1 $\mathrm{p}$. Eap1p precursor contains a secretion signal at its $\mathrm{N}$-terminus (amino acids 1-30) and a GPI attachment signal $(\omega)$ at its Cterminus (amino acids 1075-1121). The open boxes on the left denote amino acids 31-140, the putative yeast-yeast adhesion domain. Boxes with vertical lines denote amino acids 141-675, the $\mathrm{N}$-terminal serine/threonine-rich domain with repeats. Grey boxes denote amino acids 676-748, the domain that is homologous to the putative yeast-yeast adhesion domain. Hatched boxes denote amino acids 749-997, the C-terminal Ser/Thr-rich domain with repeats. The box with horizontal lines denotes amino acids 998-1074, the C-terminal region. The diagram is drawn to scale. SP, signal peptide; $\mathrm{HA}$, haemagglutinin epitope of influenza virus

carrying an empty vector was unable to invade agar on synthetic medium lacking uracil, but wild-type EAP1 expression induced invasive growth in the flo8 $\Delta$ strain (Fig. 4). The expression of any of the EAP1 mutants lacking the N-terminal domain was not able to restore invasiveness to the haploid flos $\Delta$ strain, suggesting that the N-terminal domain of Eaplp was required for agar invasion (Fig. 4a). Expression of all C-terminal EAP1 mutants, except HAEap1p $\Delta 4$ C.GPI, was able to restore invasiveness to the haploid flos $\Delta$ strain (Fig. 4b). Presumably the N-terminal (a)
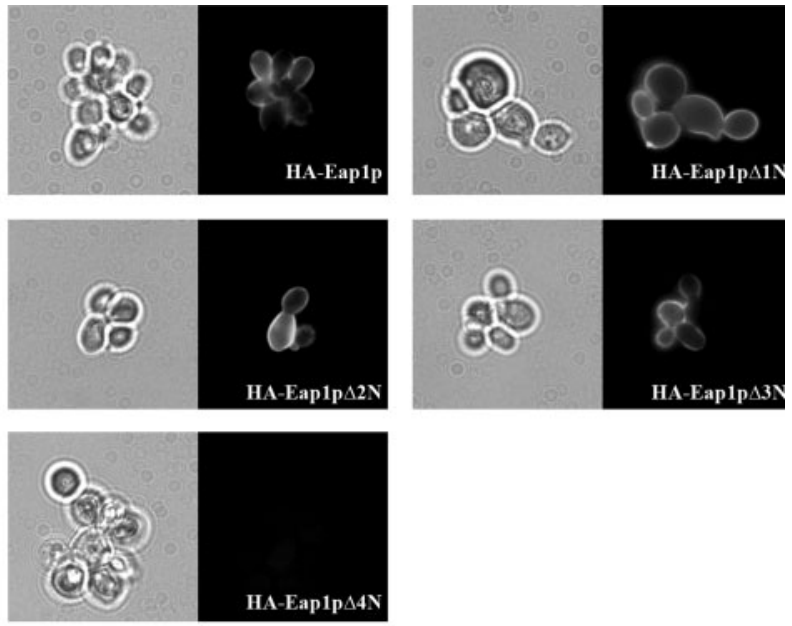

(b)
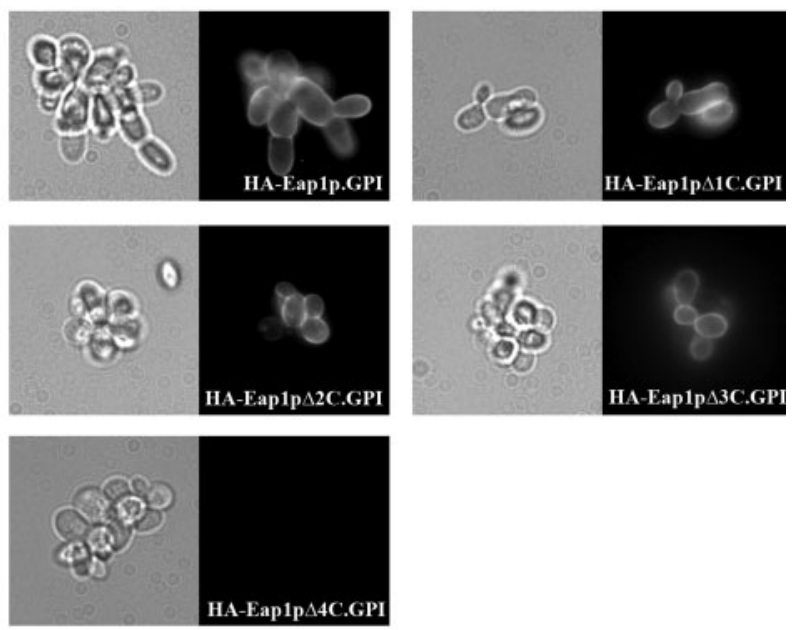

(c)
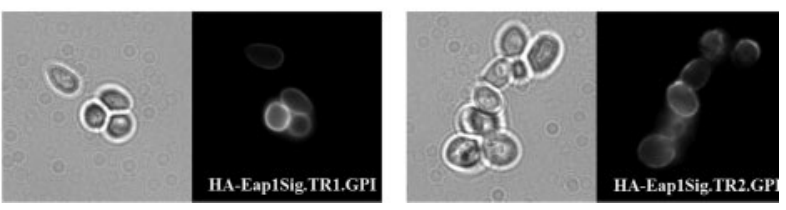

Fig. 3. Surface expression of mutant Eap1p proteins visualized by phase-contrast and epifluorescence microscopy of $S$. cerevisiae strains with anti-HA antibody. (a) Strains expressing HA-Eap1p, HA-Eap $1 \mathrm{p} \Delta 1 \mathrm{~N}, \mathrm{HA}-\operatorname{Eap} 1 \mathrm{p} \Delta 2 \mathrm{~N}, \mathrm{HA}-\operatorname{Eap} 1 \mathrm{p} \Delta 3 \mathrm{~N}$ and HAEap1p $\Delta 4 \mathrm{~N}$. (b) Strains expressing HA-Eap1p.GPI, HAEap1p $\Delta 1$ C.GPI, HA-Eap1p $\Delta 2$ C.GPI, HA-Eap1p $\Delta 3$ C.GPI and HA-Eap1p $\Delta 4$ C.GPI. (c) Strains expressing HA-tagged N-terminal Ser/Thr-rich tandem repeat domain (HA-Eap1Sig.TR1.GPI) and C-terminal Ser/Thr-rich tandem repeat domain (HAEap1Sig.TR2.GPI) in the presence of Eap1p signal peptide and GPI attachment signal. Cells were cultured in minimal medium containing galactose for $8 \mathrm{~h}$ at $30{ }^{\circ} \mathrm{C}$.

domain of HA-Eaplp $\Delta 4$ C.GPI was not exposed to the extracellular environment; the HA tag on this protein was not accessible to an anti-HA antibody (Fig. 3b). To further investigate the role of the N-terminal domain of Eaplp in 

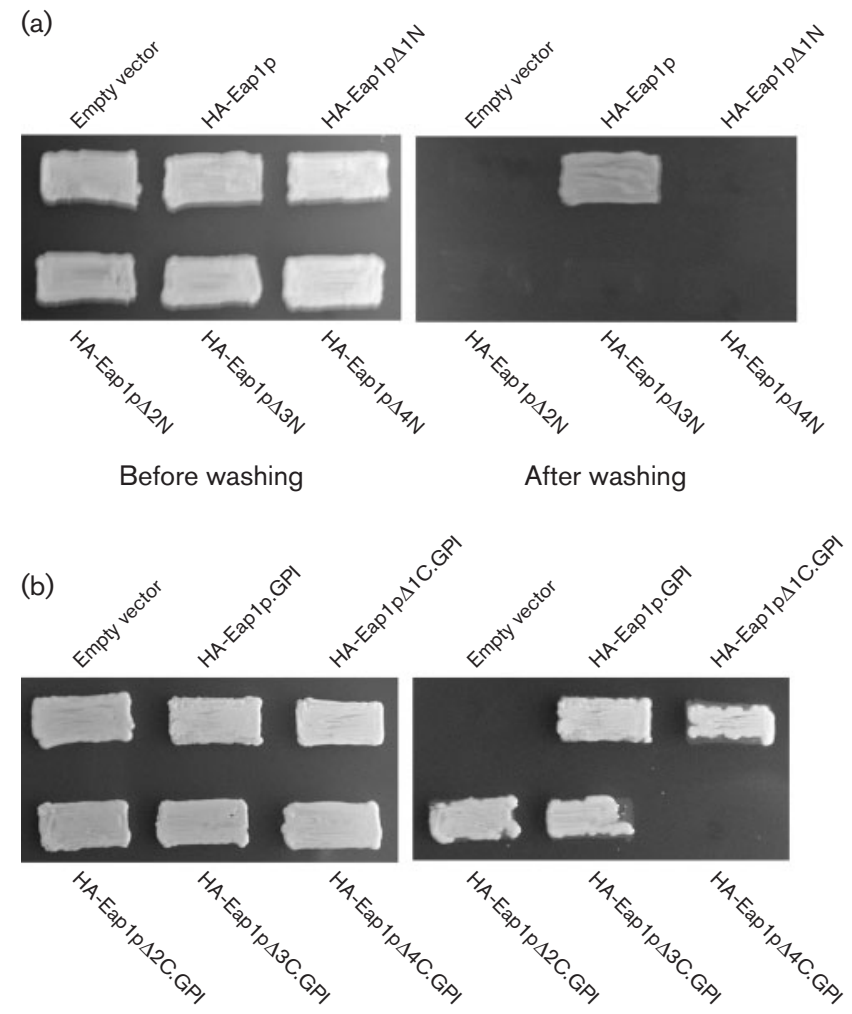

Before washing

After washing

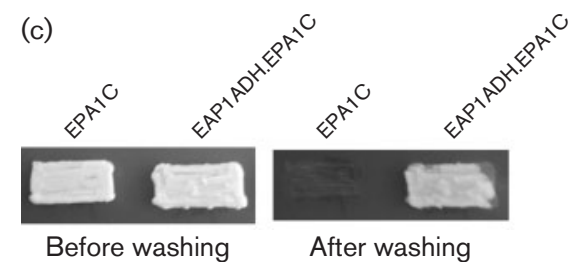

Fig. 4. Invasive growth of haploid S. cerevisiae strain SPY308 (flo8D) expressing Eap1 mutant proteins. (a) SPY308 was transformed with empty vector and with plasmids encoding HAEap1p, HA-Eap1p $\Delta 1 \mathrm{~N}, \mathrm{HA}-\operatorname{Eap} 1 \mathrm{p} \Delta 2 \mathrm{~N}, \mathrm{HA}-\mathrm{Eap} 1 \mathrm{p} \Delta 3 \mathrm{~N}$ and HAEap $1 \mathrm{p} \triangle 4 \mathrm{~N}$. (b) SPY308 was transformed with empty vector and plasmids encoding HA-Eap1p.GPI, HA-Eap1p $\Delta 1$ C.GPI, HAEap1p $\Delta 2$ C.GPI, HA-Eap1p $\Delta 3$ C.GPI and HA-Eap1p $\Delta 4$ C.GPI. (c) SPY308 was transformed with a vector encoding the Cterminal Ser/Thr-rich domain of Candida glabrata Epa1p (EPA1C) and a vector encoding the $\mathrm{N}$-terminal putative yeast-yeast adhesion domain of Eap1p and EPA1C fusion protein (EAP1ADH.EPA1C). All strains were patched on SC-Ura medium containing galactose and allowed to grow at $30{ }^{\circ} \mathrm{C}$ for 2 days. The plates were photographed and then held under gently running water for several minutes and photographed again.

haploid invasive growth, we expressed a construct encoding a chimera protein of the N-terminal domain of Eap1p and the C-terminal Ser/Thr-rich tandem repeat domain of Candida glabrata Epalp. The C-terminal Ser/ Thr-rich domain of Epalp is able to project the N-terminal domain of Epalp through the permeability barrier of cell wall and into the extracellular environment (Frieman et al., 2002). Expression of the C-terminal domain of Epalp alone did not restore the ability of the haploid flos $\Delta$ strain to invade agar, but the strain carrying the construct encoding the Eaplp-Epalp chimera was able to invade agar (Fig. 4c), suggesting that the $\mathrm{N}$-terminal domain of Eaplp is able to mediate invasive growth if projected beyond the cell surface.

We propose that the invasive growth assay as performed in this study reflects the strength of yeast cell-cell and cellagar adhesion because the patched cells in lower layers adhere to the agar substrate and bind the cells in upper layers, preventing them from washing away. To follow up on these results, we tested the ability of yeast cells expressing various Eaplp mutants to form cell aggregates in suspension. Any strain expressing an Eaplp mutant with an accessible $\mathrm{N}$-terminal domain formed large cell aggregates, while control strains and strains expressing Eap1p mutants lacking the $\mathrm{N}$-terminal domain grew as single cells or small clusters, further implying a role of the $\mathrm{N}$-terminal domain of Eaplp in mediating yeast cell-cell adhesion (Fig. 5).

\section{The two Ser/Thr-rich domains containing tandem repeats are required for adhesion to polystyrene}

Expression of EAP1 in S. cerevisiae increased adhesion to polystyrene and deletion of EAP1 in C. albicans reduced adhesion to polystyrene (Li \& Palecek, 2003; Li et al., 2007). S. cerevisiae haploid flo8s strains expressing the Nterminal and the C-terminal Eap1p mutants that lack one of the two Ser/Thr-rich tandem repeat domains (HAEap $1 \mathrm{p} \Delta 4 \mathrm{~N}$ and HA-Eap1p $\Delta 4 \mathrm{~N}$.GPI) exhibited reduced adhesion to polystyrene compared to the wild-type and the Eap1p mutants that contain both tandem repeat domains (Fig. 6a, b; $P<0.05$ ). We also transformed the haploid flos $\Delta$ strain with constructs encoding the N-terminal (HAEap1Sig.TR1.GPI) and C-terminal (HA-Eap1Sig.TR2.GPI) tandem repeat domains of Eaplp and found that the adhesion to polystyrene was restored by expressing these two tandem repeat domains bounded by the signal peptide and GPI anchor sequences of Eap1p (Fig. 6c; $P<0.01$ ). $S$. cerevisiae cells expressing the Eap1-Epal chimera did not exhibit enhanced adhesion to polystyrene as compared to cells expressing the C-terminal Ser/Thr-rich domain of $C$. glabrata Epalp (Fig. 6c). These results suggest that the two Ser/Thr-rich tandem repeat domains are sufficient to mediate adhesion to polystyrene.

\section{The $\mathrm{N}$-terminal tandem repeat domain mediates adhesion to mammalian cells}

Expression of EAP1 in S. cerevisiae permitted yeast cell attachment to human HEK293 kidney epithelial cells, and deletion of EAP1 in C. albicans reduced yeast cell adhesion to HEK293 cells (Li \& Palecek, 2003; Li et al., 2007). To identify the domains of Eaplp involved in adhesion to 
(a)
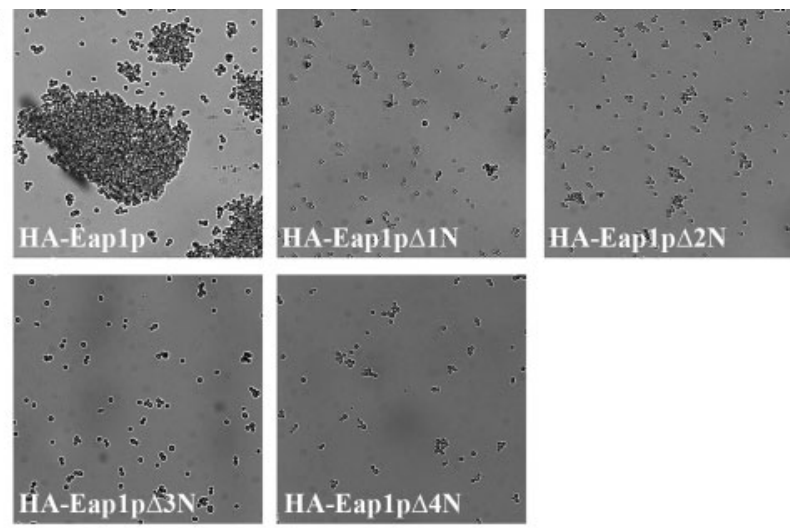

(b)
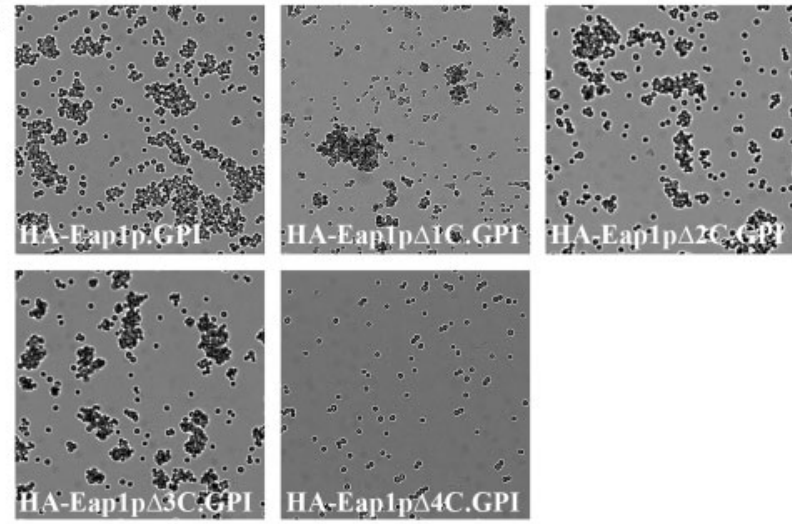

(c)

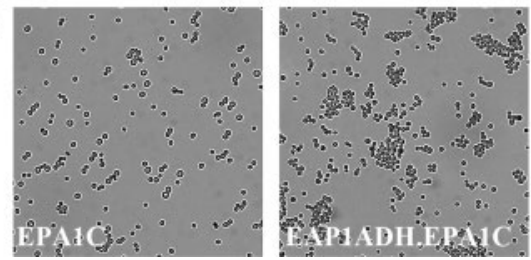

Fig. 5. Photomicrographs of yeast cell-cell adhesion. S. cerevisiae strain SPY308 (flo8A) was transformed with plasmids encoding the proteins indicated and grown overnight in liquid SC-Ura medium containing galactose. Yeast cell aggregates were visualized by photomicroscopy. (a) HA-Eap1p, HA-Eap $1 \mathrm{p} \Delta 1 \mathrm{~N}$, HA-Eap1p $\Delta 2 \mathrm{~N}, \mathrm{HA}-\operatorname{Eap} 1 \mathrm{p} \Delta 3 \mathrm{~N}$ and HA-Eap1p $\Delta 4 \mathrm{~N}$. (b) HAEap1p.GPI, HA-Eap1p $\Delta 1$ C.GPI, HA-Eap1p $\Delta 2$ C.GPI, HAEap1p $\Delta 3$ C.GPI and HA-Eap1p $\Delta 4$ C.GPI. (c) EPA1C (the Cterminal Ser/Thr-rich domain of C. glabrata Epa1p) and EAP1ADH.EPA1C (the N-terminal putative yeast-yeast adhesion domain of Eap1p and EPA1C fusion protein).

mammalian cells, we expressed the N-terminal and Cterminal EAP1 mutants in a haploid flo8s strain and quantified the yeast adhesion to mammalian HEK293 cells. HA-Eaplp induced adhesion of the flo8s strain to HEK293 cells, but deletion of the Eaplp N-terminal tandem repeat domain dramatically reduced this adhesion (Fig. 7a, b; $P<0.01)$. Interestingly, deletion of the $\mathrm{N}$-terminal domain, which was required for adhesion to yeast cells, did not reduce adhesion to HEK293 cells (Fig. 7a). Likewise, (a)

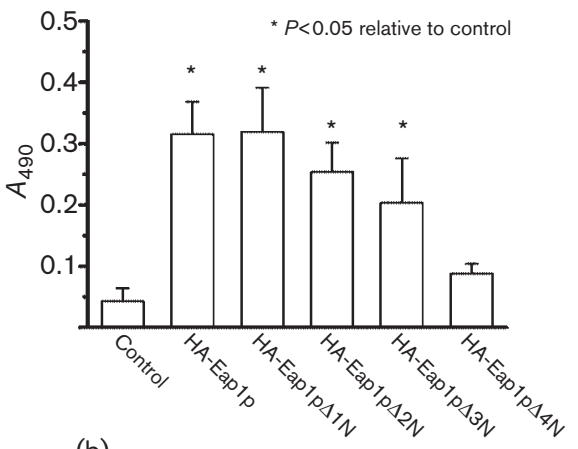

(b)

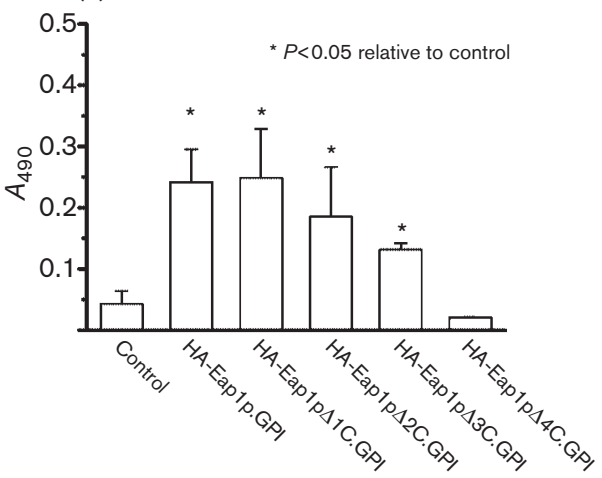

(c)

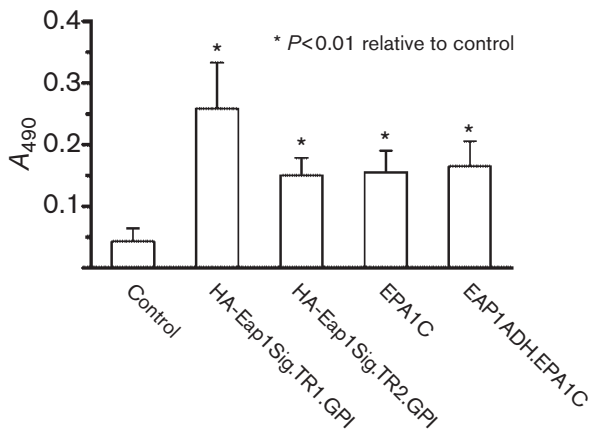

Fig. 6. Adhesion to polystyrene of haploid $S$. cerevisiae strain SPY308 (flo8 $\Delta$ ) expressing Eap1p mutant proteins. (a) SPY308 was transformed with empty vector (control) and plasmids encoding HA-Eap1p, HA-Eap1p $\Delta 1 \mathrm{~N}$, HA-Eap1p $\Delta 2 \mathrm{~N}$, HAEap $1 \mathrm{p} \Delta 3 \mathrm{~N}$ and $\mathrm{HA}$-Eap1p $\Delta 4 \mathrm{~N}$. (b) SPY308 was transformed with empty vector (control) and plasmids encoding HAEap1p.GPI, HA-Eap1p $\Delta 1$ C.GPI, HA-Eap1p $\Delta 2$ C.GPI, HAEap1p $\Delta 3$ C.GPI and HA-Eap1p $\Delta 4$ C.GPI. (c) SPY308 (flo8 $\Delta$ ) was transformed with empty vector (control) and plasmids encoding HA-Eap1Sig.TR1.GPI, HA-Eap1Sig.TR2.GPI, EPA1C and EAP1ADH.EPA1C. Strains were incubated in 24-well plates for $2 \mathrm{~h}$, then plates were washed and adhesion of cells was quantified by an XTT assay. Error bars represent the standard deviations for three independent experiments, with three replicates in each experiment. An asterisk $\left(^{*}\right)$ indicates strains that adhered to a greater extent than the control $(P<0.05$ or $P<0.01$ in a twotailed Student's $t$-test).

expression of the chimera protein containing the $\mathrm{N}$ terminal domain of Eaplp and the C-terminal domain of 

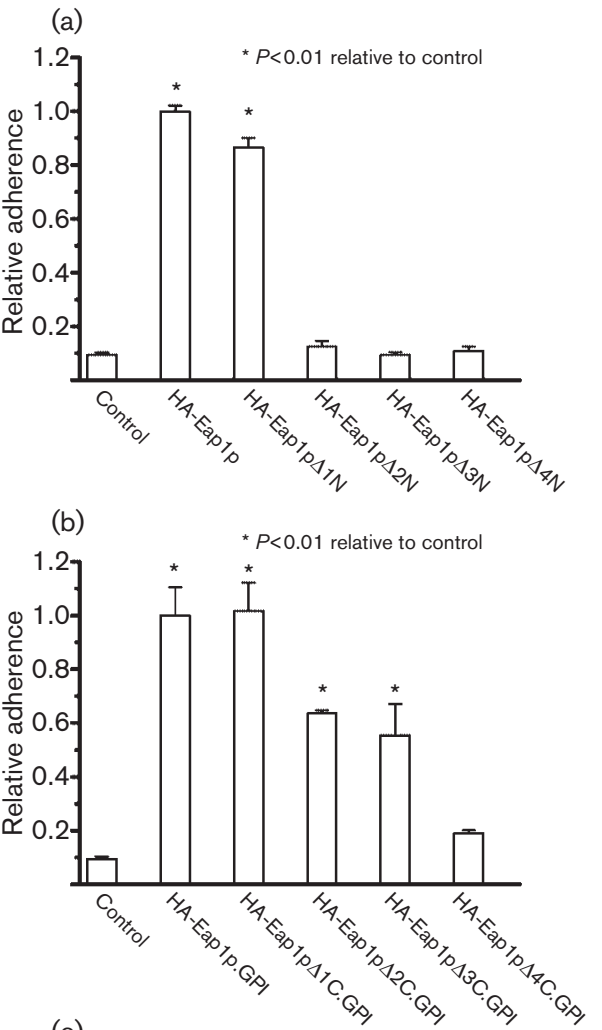

(c)

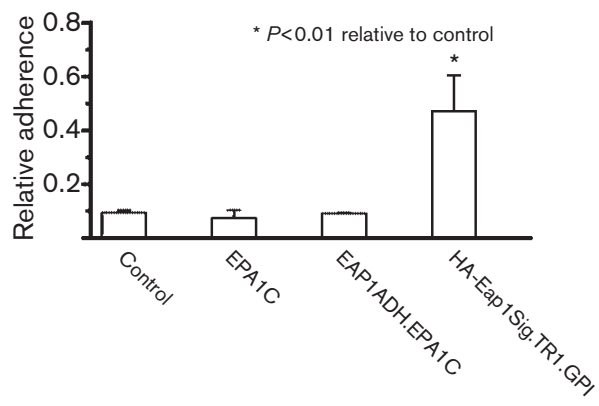

C. glabrata Epalp had no effect on adhesion to HEK293 cells (Fig. 7c), indicating that the N-terminal domain of Eaplp is substrate specific. To test whether the N-terminal tandem repeat domain was sufficient to mediate adhesion to HEK293 cells, we expressed HA-Eap1Sig.TR1.GPI and found its expression significantly enhanced the adhesion to HEK293 cells (Fig. 7; $P<0.01$ ).

\section{The $\mathbf{N}$-terminal tandem repeat domain promotes S. cerevisiae pseudohyphal growth}

Diploid flos $/$ flos cells failed to form any filaments on low-nitrogen SLAD medium (Fig. 8), and EAP1 expression restored filamentous growth to a flos $\Delta /$ flo8 $\Delta$ strain (Li \& Palecek, 2003). The expression of both HA-Eaplp (wildtype) and HA-Eap $1 \mathrm{p} \Delta 1 \mathrm{~N}$ restored the ability of a flos $\Delta /$ flos $\Delta$ strain to form pseudohyphae, indicating that the $\mathrm{N}$ terminal domain of Eaplp, which was involved in mediating yeast cell-cell adhesion, was not required for
Fig. 7. Adhesion to HEK cells of haploid $S$. cerevisiae strain SPY308 (flo8A) expressing Eap1p mutant proteins. (a) SPY308 transformed with empty vector (control) and with plasmids encoding HA-Eap1p, HA-Eap1p $\Delta 1 \mathrm{~N}, \mathrm{HA}-\operatorname{Eap} 1 \mathrm{p} \Delta 2 \mathrm{~N}$, HAEap $1 \mathrm{p} \Delta 3 \mathrm{~N}$ and HA-Eap1p $\Delta 4 \mathrm{~N}$. (b) SPY308 (flo8 $\Delta$ ) transformed with empty vector (control) and with plasmids encoding $\mathrm{HA}$ Eap1p.GPI, HA-Eap1p $\Delta 1$ C.GPI, HA-Eap1p $\Delta 2$ C.GPI, HAEap1p $\Delta 3$ C.GPI and HA-Eap1p $\Delta 4$ C. (c) SPY308 transformed with empty vector (control) and with plasmids encoding EPA1C, EAP1ADH.EPA1C and HA-Eap1Sig.TR1.GPI. In each case, cells were grown in minimal medium containing galactose and incubated on a confluent HEK293 cell monolayer for $30 \mathrm{~min}$ at $37{ }^{\circ} \mathrm{C}$. The cells were rinsed with PBS containing $\mathrm{Ca}^{2+}$ and $\mathrm{Mg}^{2+}$ to remove nonadherent cells. The HEK293 cell monolayer and associated yeast cells were detached by trypsinization and added to a YPD plate. Adhesion was quantified as the number of colonies formed on the YPD plate divided by the number of yeast cells initially added to the HEK293 monolayer, and relative adherence to the strain expressing HA-Eap1p is presented. Error bars represent the standard deviation of three separate experiments, with three replicates in each experiment. An asterisk $\left(^{*}\right)$ indicates strains that adhered to a greater extent than the control $(P<0.01$ in a two-tailed Student's $t$-test).

pseudohyphal growth (Fig. 8a). Expression of HAEap $1 \mathrm{p} \Delta 2 \mathrm{~N}, \mathrm{HA}-\operatorname{Eap} 1 \mathrm{p} \Delta 3 \mathrm{~N}$ and HA-Eap $1 \mathrm{p} \Delta 4 \mathrm{~N}$ was not able to complement the pseudohyphal growth defect of the diploid flos $\Delta /$ flos $\Delta$ strain (Fig. 8a), while expression of HA-Eap1p.GPI, HA-Eap1p $\Delta 1$ C.GPI, HA-Eap1p $\Delta 2$ C.GPI and HA-Eap $1 \mathrm{p} \Delta 3 \mathrm{C}$ did complement this pseudohyphal defect (Fig. 8b). To test whether the $\mathrm{N}$-terminal tandem repeat domain alone is able to activate the pseudohyphal growth of the flos $\Delta /$ flos strain, we transformed the diploid flo8/flo8 strain with HA-Eap1Sig.TR1.GPI and found that pseudohyphal growth was restored (Fig. 8c).

\section{DISCUSSION}

The $S$. cerevisiae genome contains about 60 putative GPIanchored proteins, of which many possess Ser/Thr-rich Cterminal domains containing tandem repeats (Caro et al., 1997). The availability of the $C$. albicans genome provides a strategy to predict ORFs that potentially encode GPI-CWP proteins based on their common sequence features. Thus far, 104 putative GPI-anchored proteins have been predicted and more than $65 \%$ of these proteins have completely unknown functions to date (Richard \& Plaine, 2007). Understanding whether these GPI-anchored proteins mediate adhesion to different materials, host cells, or other microbial cells should increase our ability to design strategies to prevent such adhesion and resulting infections.

Adherence activity of the GPI-anchored proteins has commonly been ascribed to the N-terminal domains of these proteins because deletions in these regions usually abrogate binding activity (Frieman et al., 2002; Loza et al., 2004; Sheppard et al., 2004; Staab \& Sundstrom, 1998; Wojciechowicz et al., 1993). N-terminal globular domains 
(a)

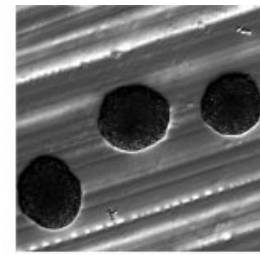

Empty vector

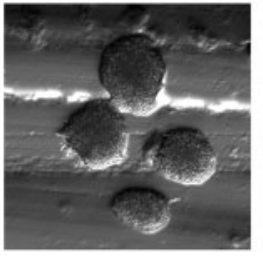

HA-Eap $1 \mathrm{p} \Delta 2 \mathrm{~N}$

(b)

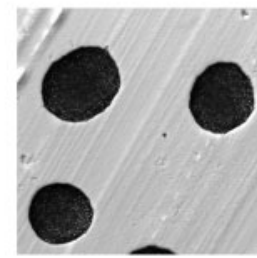

Empty vector

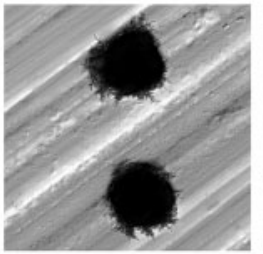

HA-Eap1p $\Delta 2$ C.GPI

(c)

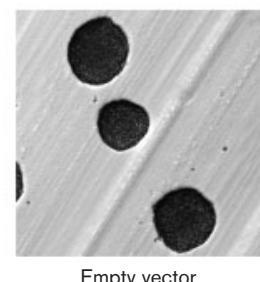

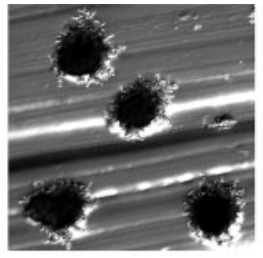

HA-Eap1p

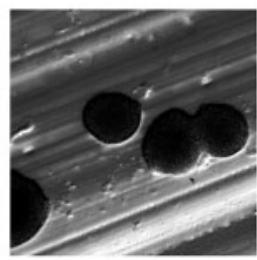

HA-Eap $1 \mathrm{p} \Delta 3 \mathrm{~N}$

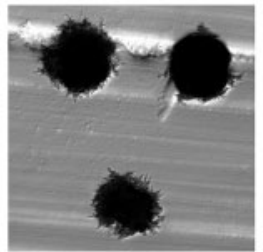

HA-Eap1p.GPI

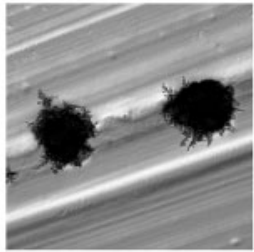

HA-Eap1p $\Delta 3$ C.GPI

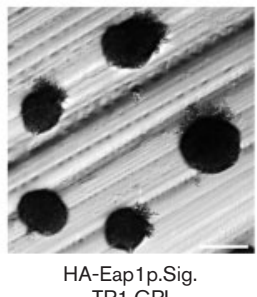

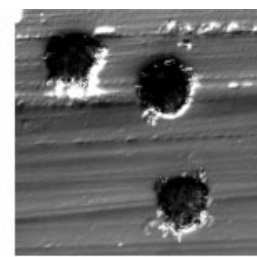

HA-Eap $1 \mathrm{p} \Delta 1 \mathrm{~N}$

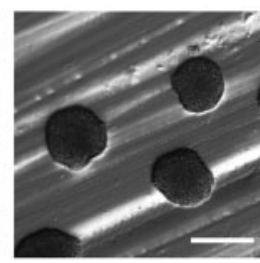

HA-Eap $1 \mathrm{p} \Delta 4 \mathrm{~N}$

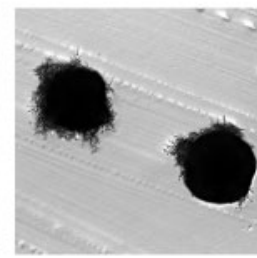

HA-Eap $1 p \Delta 1$ C.GPI

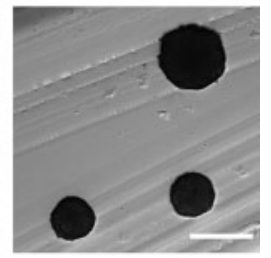

HA-Eap 1p $\Delta 4$ C.GPI
Fig. 8. Pseudohyphal formation in diploid $S$. cerevisiae strain SPY311 (flo8 $\Delta / f / 08 \Delta$ ) expressing Eap1p mutant proteins. (a) SPY311 transformed with empty vector and with plasmids encoding HA-Eap1p, HA-Eap1p $\Delta 1 \mathrm{~N}, \mathrm{HA}-\mathrm{Eap} 1 \mathrm{p} \Delta 2 \mathrm{~N}, \mathrm{HA}-$ Eap $1 \mathrm{p} \Delta 3 \mathrm{~N}$ and $\mathrm{HA}-\mathrm{Eap} 1 \mathrm{p} \Delta 4 \mathrm{~N}$. (b) SPY311 transformed with empty vector and with plasmids encoding HA-Eap1p.GPI, HAEap 1p $\Delta 1$ C.GPI, HA-Eap1p $\Delta 2$ C.GPI, HA-Eap1p $\Delta 3$ C.GPI and HA-Eap1p 4 4C.GPI. (c) SPY311 transformed with empty vector and with a plasmid encoding HA-Eap1.Sig.TR1.GPI. Cells were streaked onto the low-nitrogen SLAD medium containing galactose. Colonies were allowed to grow at $30{ }^{\circ} \mathrm{C}$ for 2 days and then photographed. Scale bars, $0.2 \mathrm{~mm}$.

bind peptide or sugar ligands, with millimolar to nanomolar affinities. These affinities and the location of adhesins and ligands at the cell surface determine microscopic and macroscopic characteristics of cell-cell associations (Dranginis et al., 2007). Here, we demonstrated that the N-terminal domain of Eaplp contains a ligand-binding domain mediating adhesion to yeast cells. This domain is also capable of rescuing the invasive defect of a haploid floss S. cerevisiae strain. The increase in invasion upon expression of Eaplp domains may be the result of the increased cell-cell adhesion. Numerous mutations that increase cell-cell adhesion via FLO11dependent or FLO11-independent mechanisms in $S$. cerevisiae also enhance invasive growth (Guo et al., 2000; Palecek et al., 2000; Svarovsky \& Palecek, 2005; Vyas et al., 2003).

The tandem repeats in Eaplp appear to have no direct role in yeast-yeast binding, but instead may project the $\mathrm{N}$ terminal ligand-binding domains away from the body of the cell and into the extracellular environment. Previous studies also suggested that tandem-repeat-containing domains are essential for stabilizing the correct conformation of the N-terminal ligand-binding domain and contributing positively to the adherence activity mediated by members of the Als family of adhesins (Loza et al., 2004; Rauceo et al., 2006). Our data also demonstrated that the Eap1p Ser/Thr-rich domain containing tandem repeats was able to mediate adhesion to polystyrene and to mammalian epithelial cells directly, in addition to its function of projecting the $\mathrm{N}$-terminal domain into the extracellular environment. Further, the N-terminal tandem repeat domain of Eaplp was able to promote the pseudohyphal growth of $S$. cerevisiae, suggesting that this tandem repeat domain was also able to induce morphological change of this fungus. The mechanism by which Eaplp induces pseudohyphal formation in S. cerevisiae is not known, but may be related to its adhesive properties, as the endogenous S. cerevisiae adhesin Flo11p and endochitinase/endoglucanse regulation of mother-daughter separation influence filamentous differentiation (King \& Butler, 1998; Lo \& Dranginis, 1998; Pan \& Heitman, 2000). However, EAP1 expression does not appear to strongly influence morphology in C. albicans (Li et al., 2007). Our results indicate that tandem repeats of GPI-anchored proteins possess multiple functions, including modulating protein structure, mediating adhesion to certain substrates, and signalling morphological changes.

The tandem repeats are thought to trigger frequent recombination events in genes or between genes and pseudogenes, causing expansion and contraction of the gene size in S. cerevisiae, and the size variation creates quantitative alterations in phenotypes (Verstrepen et al., 2005). Different clinical isolates of C. albicans have differing numbers of repeats for the same ALS gene (Hoyer, 2001). The two alleles of EAP1 in C. albicans strain SC5314 also contain differing numbers of repeats in the Nterminal tandem repeat domain. Our results suggest these tandem repeat domains can directly mediate adhesion in addition to their roles in generating cell-surface diversity through genetic recombination and epigenetic regulation. 


\section{ACKNOWLEDGEMENTS}

We thank Yuxin Mao and Brian Wong for providing the GFP expression plasmids and Brendan Cormack for providing the $C$. glabrata CG14 strain. This work was supported by a Whitaker Foundation research grant (RG-01-0421), with partial support from the University of Wisconsin Nanoscale Science and Engineering Center (UW-NSEC).

\section{REFERENCES}

Ahn, S. H., Acurio, A. \& Kron, S. J. (1999). Regulation of G2/M progression by the STE mitogen-activated protein kinase pathway in budding yeast filamentous growth. Mol Biol Cell 10, 3301-3316.

Al-Fattani, M. A. \& Douglas, L. J. (2004). Penetration of Candida biofilms by antifungal agents. Antimicrob Agents Chemother 48, 3291-3297.

Boder, E. T., Midelfort, K. S. \& Wittrup, K. D. (2000). Directed evolution of antibody fragments with monovalent femtomolar antigen-binding affinity. Proc Natl Acad Sci U S A 97, 10701-10705.

Calderone, R. A. \& Fonzi, W. A. (2001). Virulence factors of Candida albicans. Trends Microbiol 9, 327-335.

Caro, L. H., Tettelin, H., Vossen, J. H., Ram, A. F., van den Ende, H. \& Klis, F. M. (1997). In silicio identification of glycosyl-phosphatidylinositol-anchored plasma-membrane and cell wall proteins of Saccharomyces cerevisiae. Yeast 13, 1477-1489.

Cormack, B. P., Bertram, G., Egerton, M., Gow, N. A., Falkow, S. \& Brown, A. J. (1997). Yeast-enhanced green fluorescent protein (yEGFP): a reporter of gene expression in Candida albicans. Microbiology 143, 303-311.

Dranginis, A. M., Rauceo, J. M., Coronado, J. E. \& Lipke, P. N. (2007). A biochemical guide to yeast adhesins: glycoproteins for social and antisocial occasions. Microbiol Mol Biol Rev 71, 282-294.

Edmond, M. B., Wallace, S. E., McClish, D. K., Pfaller, M. A., Jones, R. N. \& Wenzel, R. P. (1999). Nosocomial bloodstream infections in United States hospitals: a three-year analysis. Clin Infect Dis 29, 239-244.

Frieman, M. B., McCaffery, J. M. \& Cormack, B. P. (2002). Modular domain structure in the Candida glabrata adhesin Epalp, a $\beta 1,6-$ glucan-cross-linked cell wall protein. Mol Microbiol 46, 479-492.

Fu, Y., Ibrahim, A. S., Sheppard, D. C., Chen, Y. C., French, S. W., Cutler, J. E., Filler, S. G. \& Edwards, J. E., Jr (2002). Candida albicans Als1p: an adhesin that is a downstream effector of the EFG1 filamentation pathway. Mol Microbiol 44, 61-72.

Gaur, N. K. \& Klotz, S. A. (1997). Expression, cloning, and characterization of a Candida albicans gene, ALA1, that confers adherence properties upon Saccharomyces cerevisiae for extracellular matrix proteins. Infect Immun 65, 5289-5294.

Gietz, D., St Jean, A., Woods, R. A. \& Schiestl, R. H. (1992). Improved method for high efficiency transformation of intact yeast cells. Nucleic Acids Res 20, 1425.

Guo, B., Styles, C. A., Feng, Q. \& Fink, G. R. (2000). A Saccharomyces gene family involved in invasive growth, cell-cell adhesion, and mating. Proc Natl Acad Sci U S A 97, 12158-12163.

Hawser, S. P. \& Douglas, L. J. (1995). Resistance of Candida albicans biofilms to antifungal agents in vitro. Antimicrob Agents Chemother 39, 2128-2131.

Hoyer, L. L. (2001). The ALS gene family of Candida albicans. Trends Microbiol 9, 176-180.

Jarvis, W. R. (1995). Epidemiology of nosocomial fungal infections, with emphasis on Candida species. Clin Infect Dis 20, 1526-1530.
King, L. \& Butler, G. (1998). Ace2p, a regulator of CTS1 (chitinase) expression, affects pseudohyphal production in Saccharomyces cerevisiae. Curr Genet 34, 183-191.

Kron, S. J., Styles, C. A. \& Fink, G. R. (1994). Symmetric cell division in pseudohyphae of the yeast Saccharomyces cerevisiae. Mol Biol Cell 5, 1003-1022.

Lambrechts, M. G., Bauer, F. F., Marmur, J. \& Pretorius, I. S. (1996). Muc1, a mucin-like protein that is regulated by Mss10, is critical for pseudohyphal differentiation in yeast. Proc Natl Acad Sci U S A 93, 8419-8424.

Li, F. \& Palecek, S. P. (2003). EAP1, a Candida albicans gene involved in binding human epithelial cells. Eukaryot Cell 2, 1266-1273.

Li, F. \& Palecek, S. P. (2005). Identification of Candida albicans genes that induce Saccharomyces cerevisiae cell adhesion and morphogenesis. Biotechnol Prog 21, 1601-1609.

Li, F., Svarovsky, M. J., Karlsson, A. J., Wagner, J. P., Marchillo, K., Oshel, P., Andes, D. \& Palecek, S. P. (2007). Eaplp, an adhesin that mediates Candida albicans biofilm formation in vitro and in vivo. Eukaryot Cell 6, 931-939.

Liu, H., Styles, C. A. \& Fink, G. R. (1996). Saccharomyces cerevisiae S288C has a mutation in FLO8, a gene required for filamentous growth. Genetics 144, 967-978.

Lo, W. S. \& Dranginis, A. M. (1998). The cell surface flocculin Flo11 is required for pseudohyphae formation and invasion by Saccharomyces cerevisiae. Mol Biol Cell 9, 161-171.

Lopez-Ribot, J. L. (2005). Candida albicans biofilms: more than filamentation. Curr Biol 15, R453-R455.

Loza, L., Fu, Y., Ibrahim, A. S., Sheppard, D. C., Filler, S. G. \& Edwards, J. E., Jr (2004). Functional analysis of the Candida albicans ALS1 gene product. Yeast 21, 473-482.

Mao, Y., Zhang, Z. \& Wong, B. (2003). Use of green fluorescent protein fusions to analyse the $\mathrm{N}$ - and C-terminal signal peptides of GPI-anchored cell wall proteins in Candida albicans. Mol Microbiol 50, 1617-1628.

Palecek, S. P., Parikh, A. S. \& Kron, S. J. (2000). Genetic analysis reveals that FLO11 upregulation and cell polarization independently regulate invasive growth in Saccharomyces cerevisiae. Genetics 156, $1005-1023$

Pan, X. \& Heitman, J. (2000). Sok2 regulates yeast pseudohyphal differentiation via a transcription factor cascade that regulates cell-cell adhesion. Mol Cell Biol 20, 8364-8372.

Pfaller, M. A. \& Diekema, D. J. (2007). Epidemiology of invasive candidiasis: a persistent public health problem. Clin Microbiol Rev 20, 133-163.

Pfaller, M. A., Jones, R. N., Messer, S. A., Edmond, M. B. \& Wenzel, R. P. (1998). National surveillance of nosocomial blood stream infection due to Candida albicans: frequency of occurrence and antifungal susceptibility in the SCOPE Program. Diagn Microbiol Infect Dis 31, 327-332.

Phan, Q. T., Myers, C. L., Fu, Y., Sheppard, D. C., Yeaman, M. R., Welch, W. H., Ibrahim, A. S., Edwards, J. E., Jr \& Filler, S. G. (2007). Als3 is a Candida albicans invasin that binds to cadherins and induces endocytosis by host cells. PLoS Biol 5, e64.

Ramage, G., Vande Walle, K., Wickes, B. L. \& Lopez-Ribot, J. L. (2001). Standardized method for in vitro antifungal susceptibility testing of Candida albicans biofilms. Antimicrob Agents Chemother 45, 2475-2479.

Rauceo, J. M., De Armond, R., Otoo, H., Kahn, P. C., Klotz, S. A., Gaur, N. K. \& Lipke, P. N. (2006). Threonine-rich repeats increase fibronectin binding in the Candida albicans adhesin Als5p. Eukaryot Cell 5, 1664-1673. 
Richard, M. L. \& Plaine, A. (2007). Comprehensive analysis of glycosylphosphatidylinositol-anchored proteins in Candida albicans. Eukaryot Cell 6, 119-133.

Sambrook, J., Fritsch, E. F. \& Maniatis, T. (1989). Molecular Cloning: a Laboratory Manual, 2nd edn. Cold Spring Harbor, NY: Cold Spring Harbor Laboratory.

Sheppard, D. C., Yeaman, M. R., Welch, W. H., Phan, Q. T., Fu, Y., Ibrahim, A. S., Filler, S. G., Zhang, M., Waring, A. J. \& Edwards, J. E., Jr (2004). Functional and structural diversity in the Als protein family of Candida albicans. J Biol Chem 279, 30480-30489.

Staab, J. F. \& Sundstrom, P. (1998). Genetic organization and sequence analysis of the hypha-specific cell wall protein gene HWP1 of Candida albicans. Yeast 14, 681-686.

Staab, J. F., Bradway, S. D., Fidel, P. L. \& Sundstrom, P. (1999). Adhesive and mammalian transglutaminase substrate properties of Candida albicans Hwp1. Science 283, 1535-1538.

Svarovsky, M. J. \& Palecek, S. P. (2005). Disruption of $L R G 1$ inhibits mother-daughter separation in Saccharomyces cerevisiae. Yeast 22, $1117-1132$.
Verstrepen, K. J., Jansen, A., Lewitter, F. \& Fink, G. R. (2005). Intragenic tandem repeats generate functional variability. Nat Genet 37, 986-990.

Vyas, V. K., Kuchin, S., Berkey, C. D. \& Carlson, M. (2003). Snf1 kinases with different beta-subunit isoforms play distinct roles in regulating haploid invasive growth. Mol Cell Biol 23, 1341-1348.

Wojciechowicz, D., Lu, C. F., Kurjan, J. \& Lipke, P. N. (1993). Cell surface anchorage and ligand-binding domains of the Saccharomyces cerevisiae cell adhesion protein $\alpha$-agglutinin, a member of the immunoglobulin superfamily. Mol Cell Biol 13, 2554-2563.

Zhao, X., Oh, S. H., Yeater, K. M. \& Hoyer, L. L. (2005). Analysis of the Candida albicans Als2p and Als4p adhesins suggests the potential for compensatory function within the Als family. Microbiology 151, 1619-1630.

Zhao, X., Oh, S. H. \& Hoyer, L. L. (2007). Unequal contribution of ALS9 alleles to adhesion between Candida albicans and human vascular endothelial cells. Microbiology 153, 2342-2350.

Edited by: J. Pla 